\title{
Output Stabilization of Wind Turbine Generator by Series and Parallel Compensation Using SMES
}

\author{
T. Senjyu ${ }^{1}$, T. Kinjyo ${ }^{1}$, K. Uezato $^{1}$, H. Fujita ${ }^{2}$, and Toshihisa Funabashi ${ }^{3}$ \\ ${ }^{1}$ Department of Electrical and Electronics Engineering \\ University of the Ryukyus \\ 1 Senbaru, Nishihara-cho, Okinawa, 903-0213 (Japan) \\ phone:+81-98-895-8686, fax:+81-98-895-8708, e-mail:b984452@tec.u-ryukyu.ac.jp, uezato@eee.u-ryukyu.ac.jp \\ ${ }^{2}$ Meidensha Corporation \\ Riverside Building, 36-2, Nihonbashi Hakozakicho Chuo-ku, Tokyo, 103-8515 (Japan) \\ phone:+81-3-5641-7509, fax:+81-3-5641-9310, e-mail:funabashi-t@honsha.meidensha.co.jp \\ ${ }^{3}$ Chubu Electric Power Co., Inc. \\ 20-1 Kitasekiyama Ohdaka-cho Midori-ku Nagoya 459-8522 (Japan) \\ phone:+81-70-5970-8039, fax:+81-52-624-9207, e-mail:Fujita.Hideki@chuden.co.jp
}

\begin{abstract}
In recent year, the generating power from renewable energy sources is coming up. Particularly, wind energy conversion systems is attractive because of it's advantages such as, pollution free, no fuel cost, abundantly available in nature etc. However, the generated power and the bus voltage is always fluctuating and it mainly depends on the wind speed. A superconducting magnetic energy storage(SMES) unit is capable of controlling both the active and reactive power simultaneously and quickly. In this paper, control scheme for active and reactive output power simultaneous control and voltage control of the series and parallel compensator using SMES is proposed. It is show through simulations, that the controlling sequence of charging and discharging of the SMES coil effectively damps out the transmission line power oscillation and WTG's terminal bus voltage fluctuations.
\end{abstract}

Key words

wind turbine generators, superconducting magnetic energy storage, generating power leveling, bus voltage control

\section{INTRODUCTION}

The increased renewable energy utilization, especially photovoltaic panels using solar energy or wind turbine generators(WTGs) using wind energy, has been expected in recent years from view point of $\mathrm{CO}_{2}$ gas emission reduction and environmental conservation. There are other aspects other than cost alone for making use of WTGs for wind energy conversion systems. However, the generated power and bus voltage of WTGs is always fluctuating because the WTGs are driven by fluctuating wind. Moreover, if WTGs is installed in the end of the distribution line, an instantaneous voltage sag will become large with increase of distribution line length by influence of the inrush current at the system interconnection[1].

From such a background, the effective interconnection equipment which connects a power system and wind energy conversion systems is required. This paper is considering introduction of superconducting magnetic energy storage(SMES) as effective interconnection equipment which solves the various problem of wind energy conversion systems. SMES is capable of controlling both the active and reactive power, simultaneously and quickly by technology enhancement of power electronics apparatus. Therefore, various application for SMES to a power system from the merit of the conversion efficiency is expected. However, introduction of SMES has been hindered since the equipment production cost is high, and is required to have multifunctional in application to power system. In recent year, SMES with a high speed phase shifter have been proposed and demonstrated the usefulness[2]-[4]. Moreover, circuit configuration achieving an active and reactive power simultaneous control have been proposed by connecting the two quadrant dcchopper with a superconducting coil and dc-link capacitor by making it operate as voltage sources[5],[6].

In this paper, control scheme which achieve the damping of transmission line power oscillations and compensating of WTG's terminal bus voltage fluctuations in the wind energy conversion systems by applying the series and parallel compensation using SMES is proposed. Moreover, control scheme of the two-quadrant dc-chopper with superconducting coil is also proposed. Furthermore, it achieves damping of rapid voltage fluctuations and power oscillations by analyzing with an instantaneous value. In order to verify a control performance, some computer simulations are performed in the target wind energy conversion systems. The performed simulations are system interconnection, wind speed turbulence and three phase to ground fault of transmission line, respectively.

\section{Configuration and Control scheme of PROPOSED SMES}

The target wind energy conversion systems which introduced a SMES is shown in Fig. 1(a). As shown in Fig. 1(a), WTGs is connected to the infinite-bus-powersystem through the transmission line of line reactance $x$, and the series and parallel compensation using SMES is located at WTG's terminal bus to achieve the damping 


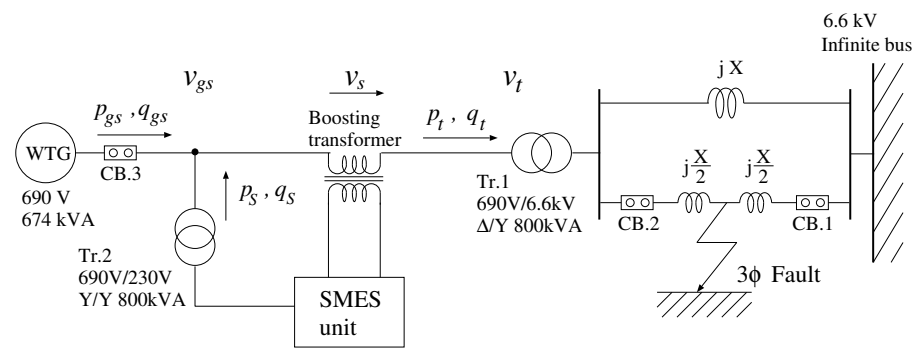

(a) Wind energy conversion systems.

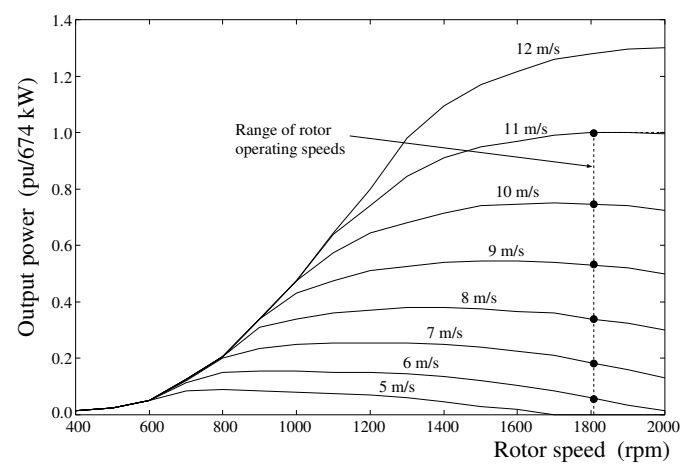

(b) Relation between windmill power and generation power $(674 \mathrm{~kW}$ rated).

Fig. 1. Power system model.

of the transmission power flow and the compensation of bus voltage. The output power of WTGs is determined by the output characteristic of Fig. 1(b)[7]. Tables 1 and 2 are parameter of WTGs(or squirrel-cage induction generators) and specification of SMES, respectively.

Configuration of the series and parallel compensation using SMES is shown in Fig. 2. It consist of a combination of series and shunt devices, the dc terminals of which are connected to a common two quadrant dc-chopper with a superconducting coil and dc-link capacitor. Control objective of the series device is suppressing the fluctuation of WTG's terminal bus voltage $v_{g s}$ by controlling the output voltage of boosting transformer $v_{s}$. Control objective of the shunt device is suppressing the oscillation of transmission line power $p_{t}$ by performing a simultaneous control of instantaneous active and reactive output power $\left(p_{s}\right.$ and $\left.q_{s}\right)$. In addition, control objective of two-quadrant dc-chopper is maintaining a constant dc-link voltage $v_{c a p}$ by performing the electric energy charging/discharging control of a superconducting coil current $i_{s m}$. Each control conception and configuration is described in the following sections.

\section{A. Control scheme of the series inverter}

Control scheme of the series inverter is shown in Fig. 3. As shown in Fig. 3, the $d-q$ axis transformation obtains $v_{s d}$ and $v_{s q}$ from three phase output voltage of boosting transformer $v_{s a}, v_{s b}$ and $v_{s c}$. The difference of the obtained signal and the reference output voltage $\left(v_{s d r e f}\right.$ and $\left.v_{\text {sqref }}\right)$ is inputted into a PI controller. The output

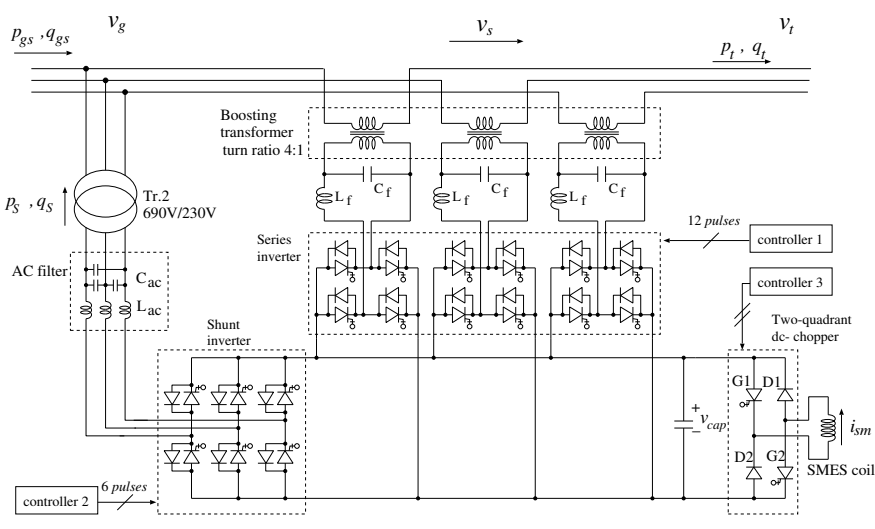

Fig. 2. Configuration of the series and parallel compensation using SMES.

signal of PI controller determines the pulse width modulation(PWM) reference voltage $v_{s a}^{*}, v_{s b}^{*}$ and $v_{s c}^{*}$ calculated from $d-q$ inverse transformation.

The reference output voltage $v_{\text {sdref }}$ and $v_{\text {sqref }}$ sets up a $d-q$ axis transmission voltage deviation $\Delta v_{t d}$ and $\Delta v_{t q}$. The reason for having set up $\Delta v_{t d}$ and $\Delta v_{t q}$ as the reference output voltage is shown below. If the output voltage from a boosting transformer is zero, a WTG's terminal bus voltage $v_{g s}$ and transmission voltage $v_{t}$ are the same. When a WTG's terminal bus voltage fluctuation $\Delta v_{g d}$ and $\Delta v_{g q}$ arises by disturbance etc., $\Delta v_{t d}$ and $\Delta v_{t q}$ is removed by $v_{s d}$ and $v_{s q}$ as shown in eq. (1).

$$
\left.\begin{array}{l}
\Delta v_{g d}=\Delta v_{t d}-v_{s d}=0 \\
\Delta v_{g q}=\Delta v_{t q}-v_{s q}=0
\end{array}\right\}
$$

When $v_{s d}$ and $v_{s q}$ tracks $v_{s d r e f}$ and $v_{s q r e f}, v_{g d}$ and $v_{g q}$ is maintained at constant voltage.

\section{B. Control scheme of the shunt inverter}

In control objective of the shunt inverter, if a oscillation components $\Delta p_{t}$ and $\Delta q_{t}$ is contained in the output power of WTGs by disturbance which arises from wind speed fluctuation, as shown in eq. (2), a transmission line power $p_{t}$ can uniformly maintained by absorbing or releasing active and reactive power $\left(p_{s}\right.$ and $\left.q_{s}\right)$ from SMES.

$$
\left.\begin{array}{l}
\Delta p_{t}=\Delta p_{g s}-p_{s}=0 \\
\Delta q_{t}=\Delta q_{g s}-q_{s}=0
\end{array}\right\}
$$

Control scheme of the shunt inverter is shown in Fig. 4. As shown in Fig. 4, the instantaneous active and reactive output power of the shunt inverter is calculated from $d-q$ axis voltage and current obtained by $d-q$ axis transformation. The difference of the obtained signal and the reference output power $p_{\text {sref }}$ or $q_{s r e f}$ is inputted into a PI controller. The output signal of PI controller determines the PWM reference current $i_{s a}^{*}, i_{s b}^{*}$ and $i_{s c}^{*}$ 


\begin{tabular}{lr} 
rated output & $674 \mathrm{~kW}$ \\
rated line-to-line voltage & $690 \mathrm{~V}$ \\
rated frequency & $60 \mathrm{~Hz}$ \\
pole number $P$ & $4 \mathrm{pole}$ \\
inertia coefficient $J$ & $687 \mathrm{~kg} \cdot \mathrm{m}^{2}$ \\
stator resistance $r_{s}$ & $0.019 \mathrm{p} \cdot \mathrm{u}$. \\
stator leakage reactance $x_{l s}$ & $0.220 \mathrm{p} \cdot \mathrm{u}$. \\
rotor resistance $r_{r}$ & $0.016 \mathrm{p} \cdot \mathrm{u}$. \\
rotor leakage reactance $x_{l r}$ & $0.190 \mathrm{p} \cdot \mathrm{u}$. \\
excitation reactance $x_{m}$ & $7.300 \mathrm{p} \cdot \mathrm{u}$. \\
\hline
\end{tabular}

TABLE II

SPECIFICATION OF SERIES AND PARALLEL COMPENSATION USING SMES.

\begin{tabular}{lr}
\hline rated current & $500 \mathrm{~A}$ \\
coil inductance & $5 \mathrm{H}$ \\
filtering capacitance & $1.2 \mathrm{mF}$ \\
stored possible power & $625 \mathrm{~kW} / 174 \mathrm{Wh}$ \\
AC-filtering inductance $L_{a c}$ & $2 \mathrm{mH}$ \\
AC-filtering capacitance $C_{a c}$ & $50 \mu \mathrm{F}$ \\
AC-filtering inductance $L_{f}$ & $0.2 \mathrm{mH}$ \\
AC-filtering capacitance $C_{f}$ & $10 \mu \mathrm{F}$ \\
carrier frequency of the inverters & $2000 \mathrm{~Hz}$ \\
carrier frequency of the dc-chopper & $500 \mathrm{~Hz}$ \\
\hline
\end{tabular}

calculated from $d-q$ axis inverse transformation.

The determination process of $p_{\text {sref }}$ and $q_{s r e f}$ is described. At first, an instantaneous active and reactive output power of WTGs $p_{g s}+\Delta p_{g}$ and $q_{g s}+\Delta q_{g}$ are detected. Low-pass-filter(LPF) and phase compensator shown in Fig. 4 is the filter which remove the oscillation component. The filter is designed so that an instantaneous active output power $p_{s}$ of the shunt inverter in steady-state could be zero. Inputting a detected signal $p_{g s}+\Delta p_{g}$ into the filter, the filter outputs the signal removed a oscillation component. The difference of a detected signal and a removed signal is oscillation component $\Delta p_{g}$. The reference reactive power $q_{s r e f}$ is determined by the difference of the detected signal $q_{g s}+\Delta q_{g}$ and arbitrary reference reactive power of transmission line $q_{t r e f}$. If an instantaneous active and reactive output power $\left(p_{s}\right.$ and $\left.q_{s}\right)$ of the shunt inverter tracks $p_{s r e f}\left(\Delta p_{g}\right)$ and $q_{s r e f}$, the oscillation components of $p_{g s}$ and $q_{g s}$ is removed. The parameters of PI controller used in simulation are shown in Table. 3 .

\section{Control scheme of the two-quadrant dc-chopper}

Control conceptual diagram of charging or discharging energy is shown in Fig. 5, and control scheme of the twoquadrant dc-chopper which achieves a constant dc-link voltage $v_{c a p}$ control is shown in Fig. 6 . In the char-

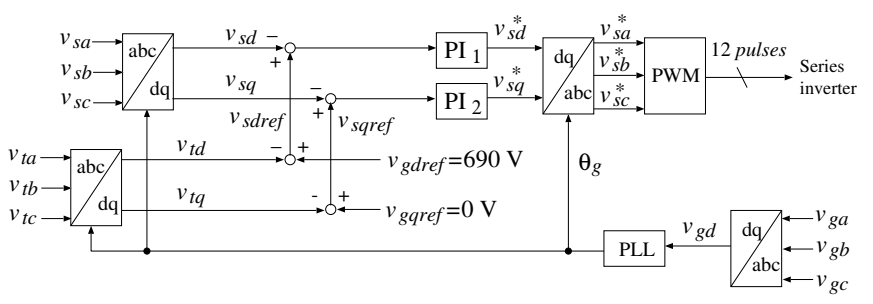

Fig. 3. Control scheme of the series inverter(controller 1).

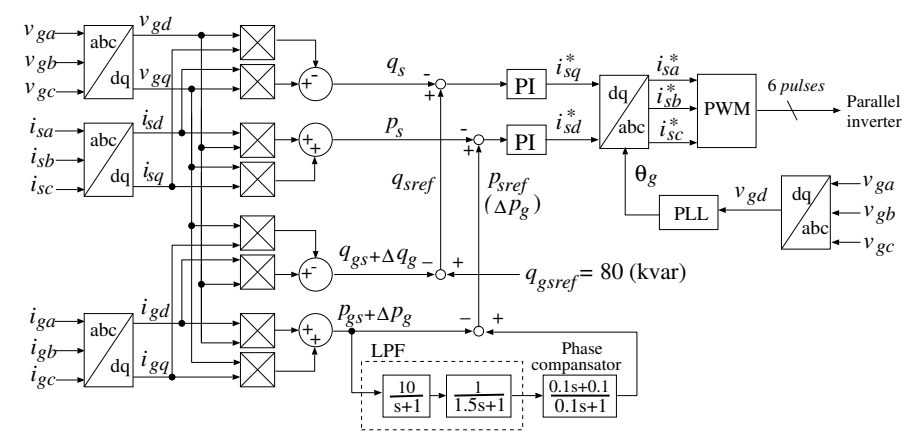

Fig. 4. Control scheme of the shunt inverter(controller 2).

acteristic of this chopper shown in Fig. 5, an electric energy is charged ( $v_{c a p}$ is decreased) when Gate-TurnOff(GTO) thyristor G1 and G2 is $\mathrm{ON}(\mathrm{D} 1$ and D2 is $\mathrm{OFF})$, an electric energy is discharged $\left(v_{c a p}\right.$ is increased) when G1 and G2 is OFF(D1 and D2 is ON). A constant dc-link voltage $v_{c a p}$ control is performed by PWM duty factor control using the characteristic. In Fig. 6, $v_{c a p}$ is decreased when $0<d<50 \%, v_{c a p}$ is increased when $50 \leq d<100 \%$, where a magnitude of carrier wave signal is $100 \%$. The PWM reference signal is determined by the difference of LPF output signal and dc-link voltage reference $v_{\text {capref }}$ as shown in Fig. 6. A output of comparator depending on comparison of the PWM reference signal and carrier wave signal is 1 when carrier wave signal is greater than the reference signal, and 0 when carrier wave signal is less than the reference signal.

\section{Simulation Results}

The effectiveness of the proposed control schemes is demonstrated through computer simulations by considering the wind power generation system shown in Fig. 1. Each parameters of transmission line and transformers used in the simulations are shown in Tables 3 and 4 . The disturbances to the wind power generation system is the transmission line power oscillations and the generator's terminal bus voltage fluctuation at the system interconnection, a wind speed fluctuation, and a three phase to ground fault.

\section{A. Simulation results of system interconnection and wind speed turbulence}

The simulation sequence is shown below: 


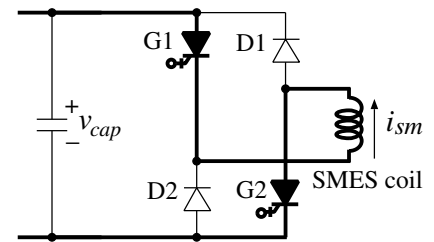

(a) Charging mode G1,G2 - ON (D1,D2 - OFF)

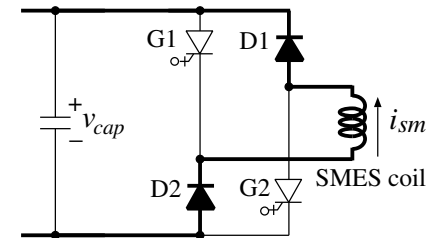

(b) Discharging mode $\mathrm{G} 1, \mathrm{G} 2$ - OFF (D1,D2 - ON)
Fig. 5. Control concept of charging and discharging.

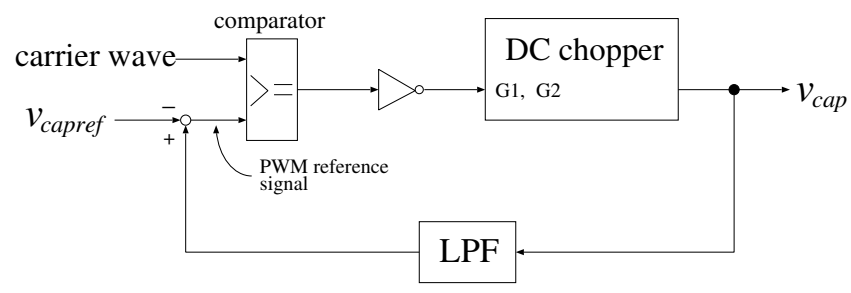

Fig. 6. Control scheme of two-quadrant dc-chopper(controller 3).

$$
\begin{aligned}
& \text { i) } t=1 \quad \text { : system interconnection with a con- } \\
& \text { stant wind speed, } \\
& \begin{array}{ll}
\text { ii) } 1.5 \leq t \leq 4.5 \quad: \text { wind speed turbulence which fre- } \\
\text { quency is } 1[\mathrm{~Hz}] \text { arises, } \\
\text { iii) } 4.5 \leq t \quad: \text { a constant wind speed. }
\end{array}
\end{aligned}
$$

Fig. 7 shows the simulation results at interconnection. In Figs. 7 (a) ,(b) and (c), solid line and dashed line shows the simulation results with the installing SMES and the not installing SMES, respectively. Fig. 7(a) can be seen that the installing SMES can compensate effectively the WTG's terminal bus voltage fluctuation as compared to the case of the not installing SMES. And from Fig. 7(d), it can be confirmed that the series inverter of a proposed SMES is outputting the $d-q$ axis voltage $v_{s d}$ and $v_{s q}$ to compensate the generator's terminal bus $d-q$ axis voltage fluctuations. Fig. 7(b) can be seen that the installing SMES can damp effectively the transmission line power oscillation as compared to the case of the not installing SMES. And from Fig. 7(d), it can be confirmed that the shunt inverter of a proposed SMES is absorbing or releasing the active and reactive power of reverse polarity as compared with the transmission line power oscillations. As shown in Fig. 7(c), it can be confirmed that the inrush current has been suppressed due to voltage compensation of the series inverter with boosting transformer.

Fig. 8 shows the simulation results at wind speed turbulence. As shown in Fig. 8(a), wind speed turbulence simulated by making it change from $9 \mathrm{~m} / \mathrm{s}$ to $2 \mathrm{~m} / \mathrm{s}$. From Fig. 8(b) and (c), WTG's terminal bus voltage and transmission line power are controllable by a proposed SMES similarly at wind speed turbulence. Moreover, it can be confirmed that the transmission line power is con-

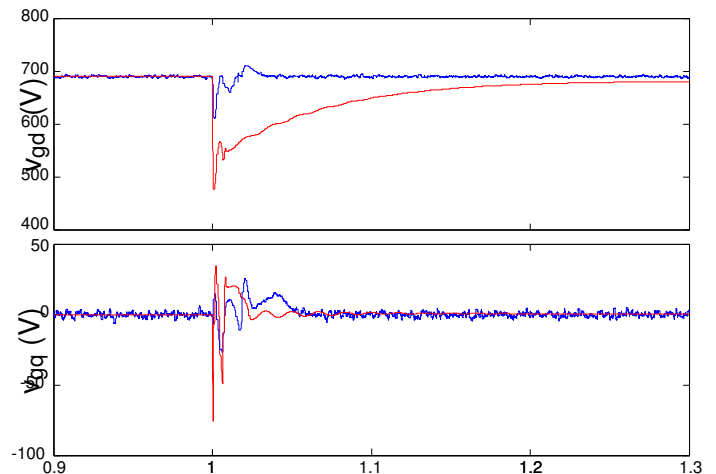

(a) WTG's terminal bus $d-q$ axis voltage.

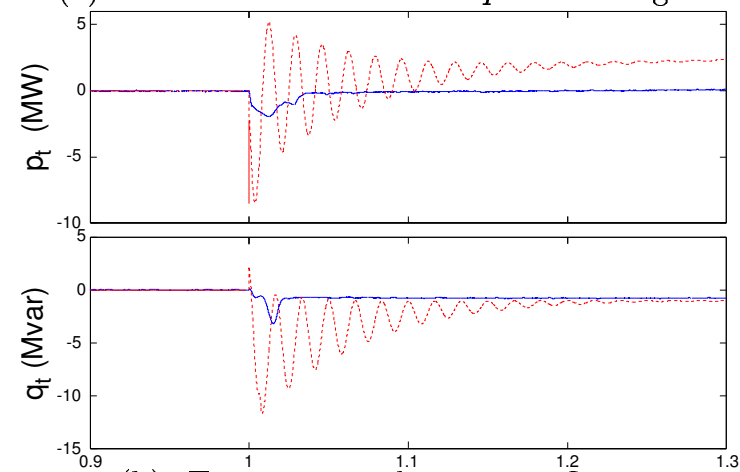

(b) Transmission line power flow.

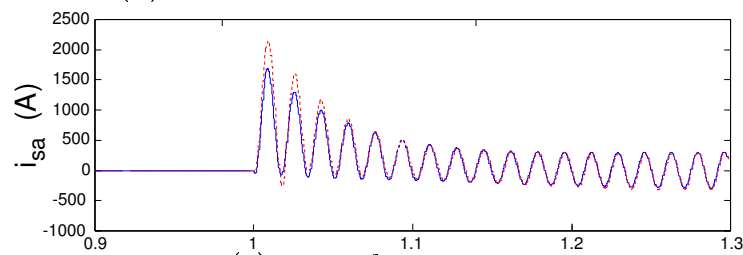

(c) Inrush current.
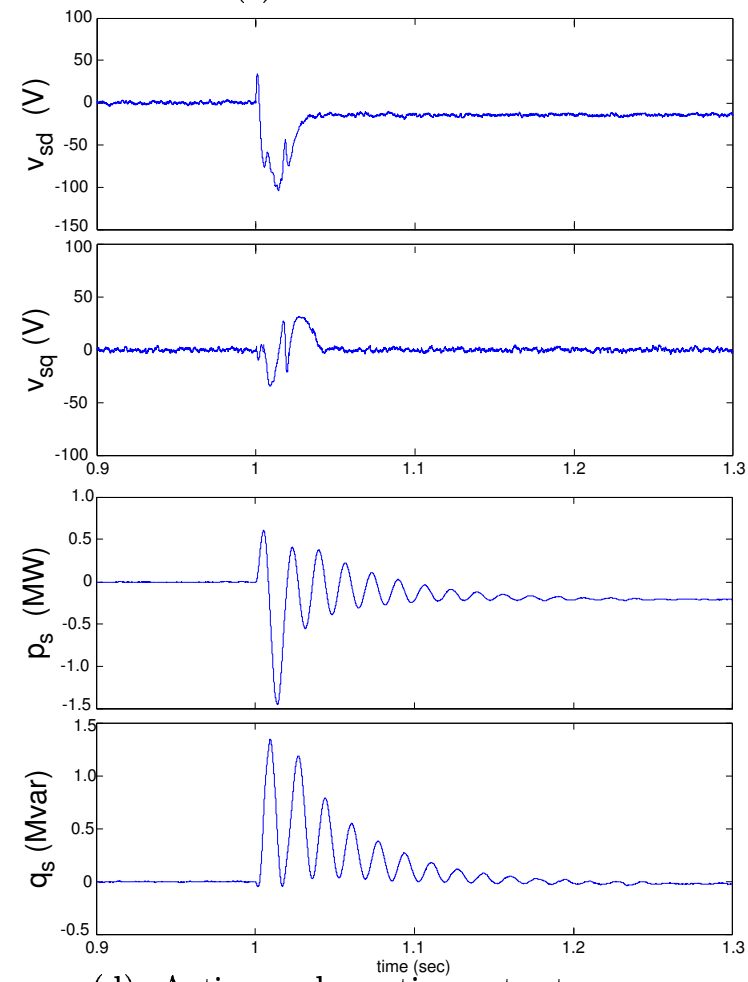

(d) Active and reactive output power of the series and parallel compensator.

Fig. 7. Simulation results at interconnection. 
TABLE III

PARAMETERS OF PI CONTROLlERS.

\begin{tabular}{l||c|c|c|c}
\hline & $\mathrm{PI}_{1}$ & $\mathrm{PI}_{2}$ & $\mathrm{PI}_{3}$ & $\mathrm{PI}_{4}$ \\
\hline Proportional gain $K_{p}$ & 2.5 & 4.5 & 1.6 & 1.6 \\
\hline Integral gain $K_{i}$ & 250 & 350 & 120 & 120 \\
\hline
\end{tabular}

TABLE IV

TRANSFORMER PARAMETERS.

\begin{tabular}{c||c|c|c|c|c|c}
\hline & $R_{1}(\mathrm{pu})$ & $L_{1}(\mathrm{pu})$ & $R_{2}(\mathrm{pu})$ & $L_{2}(\mathrm{pu})$ & $R_{m}(\mathrm{pu})$ & $L_{m}(\mathrm{pu})$ \\
\hline$T_{r 1}$ & 0.015 & 0.03 & 0.015 & 0.03 & 200 & 200 \\
\hline$T_{r 2}$ & 0.003 & 0.04 & 0.003 & 0.04 & 200 & 200 \\
\hline
\end{tabular}

(rated $\mathrm{T}_{r 1}: 800 \mathrm{kVA}-6.6 \mathrm{kV} / 690 \mathrm{~V}$, $\left.\mathrm{T}_{r 2}: 800 \mathrm{kVA}-690 \mathrm{~V} / 230 \mathrm{~V}\right)$

TABLE V

LINE PARAMETERS.

\begin{tabular}{lr}
\hline line reactance $x$ & 0.04 p.u. $/ \mathrm{km}$ \\
line length & $40 \mathrm{~km}$ \\
\hline
\end{tabular}

verging to its steady-state value at $t=8 \mathrm{sec}$ by the effect of the filter. Furthermore, Fig. 8(d) can be seen that the two-quadrant dc-chopper can maintain constant dc-link voltage $v_{c a p}$.

\section{B. Simulation results of a three-phase to ground fault}

The simulation sequence is shown below:

$$
\begin{gathered}
\text { i) } t=3 \quad \begin{array}{c}
\text { : a three phase to ground fault was ap- } \\
\text { plied a the middle of one transmission }
\end{array} \\
\text { line, } \\
\text { ii) } t=3.0667 \quad: \text { opening the faults transmission line, } \\
\text { iii) } 3.0667 \leq t \text { : the other transmission line is sending } \\
\text { power. }
\end{gathered}
$$

Fig. 9 shows the simulation results at three-phase to ground fault. As shown in Figs. 9(a) and (b), in the case of the not installing SMES, WTG's terminal bus $d$ axis voltage $v_{g d}$ is arising an instantaneous voltage sag of about $400[\mathrm{~V}]$, and the transmission line power oscillation is arising at the same time. In the case of the installing SMES, as shown in Fig. 9(d), it can be confirmed that an instantaneous output voltage sag has been compensated by outputting the $d-q$ axis voltage $v_{s d}$ and $v_{s q}$ from the series inverter, and the transmission line power oscillations has been damped by absorbing or releasing the active and reactive power from the shunt inverter. Moreover, it can be confirmed that the fault current has been suppressed by performing the voltage compensation as shown in Fig. 9(c). Furthermore, Fig. 9(d) can be seen that the two quadrant dc-chopper can maintain the constant dc-link voltage.

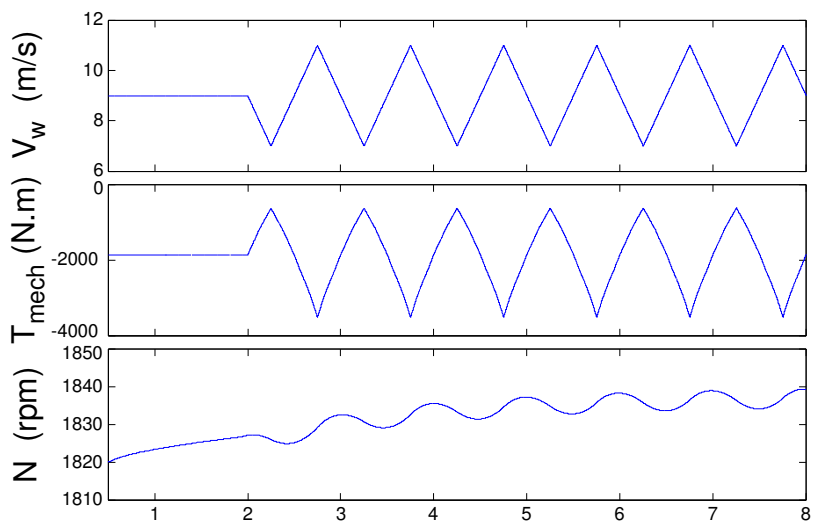

(a) Wind speed, mechanical input torque and rotor speed.

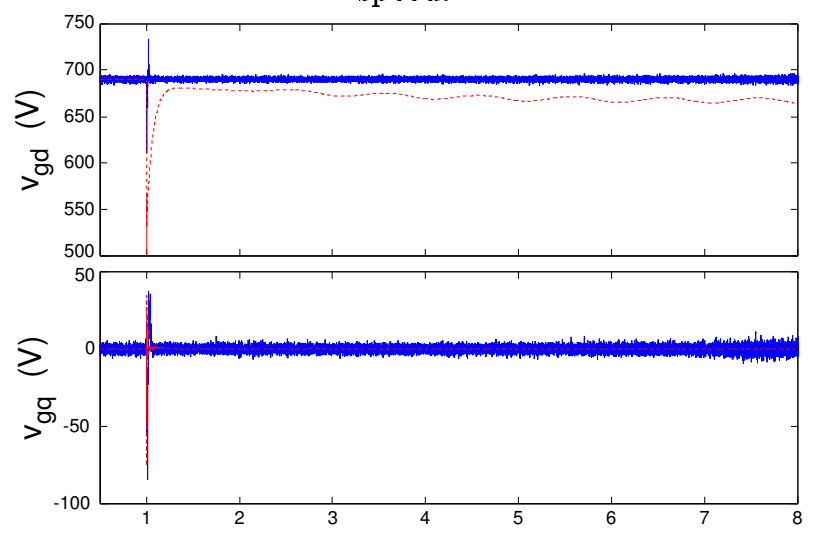

(b) WTG's terminal bus $d-q$ axis voltage.

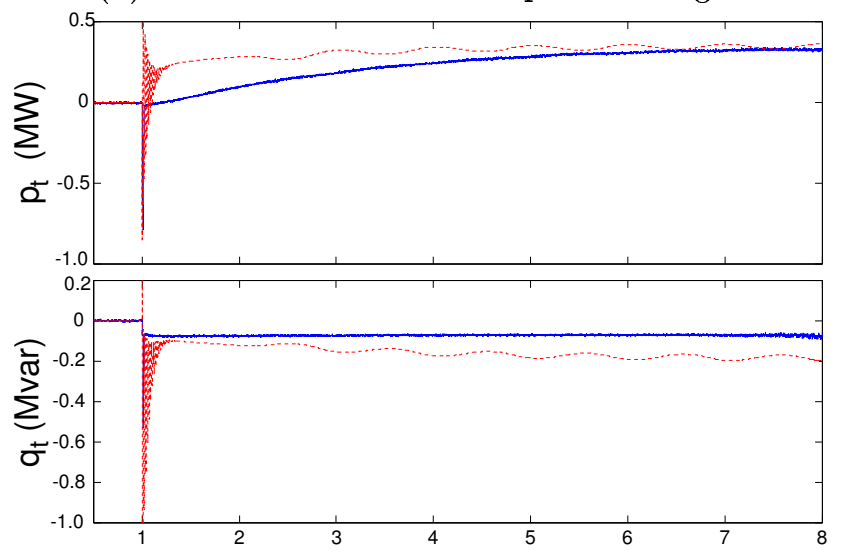

(c) Transmission line power flow.

\section{Conclusion}

In this paper, in the wind energy conversion systems, control schemes which achieve compensation of WTG's terminal bus voltage fluctuations and the damping of transmission line power oscillation by applying the series and parallel compensation using SMES was proposed. The effectiveness of the proposed control schemes was demonstrated through computer simulations. The disturbances to wind energy conversion systems was WTG's terminal bus voltage fluctuations and the transmission line power oscillations at a system interconnection, a wind speed turbulence, and three-phase to 

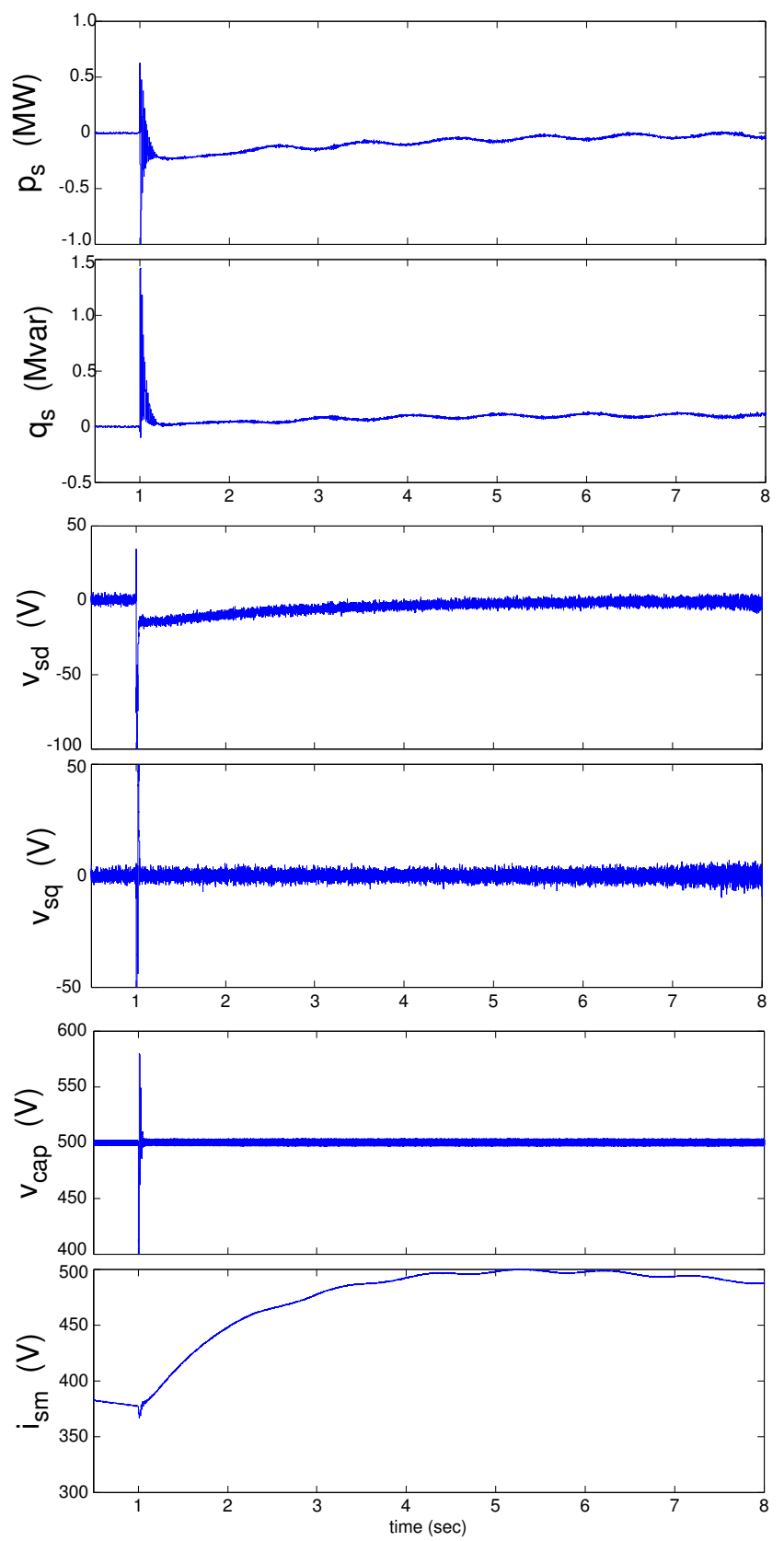

(d) Output and dc-side quantity of the series and parallel compensator.

Fig. 8. Simulation results at interconnection.

ground fault of transmission line. From simulation results, it could be confirmed that the series and parallel compensation using SMES can control effectively WTG's terminal bus voltage fluctuations and the transmission line power oscillation. Moreover, it can be confirmed that the two-quadrant dc-chopper can maintain the constant dc-link voltage.

\section{REFERENCES}

[1] Y. Sasaki, N. Harada, T. Kai, and T. Sato, "A Countermeasure against the Voltage Sag due to a Inrush Current of Wind Power Generation System Interconnecting to a Distribu-

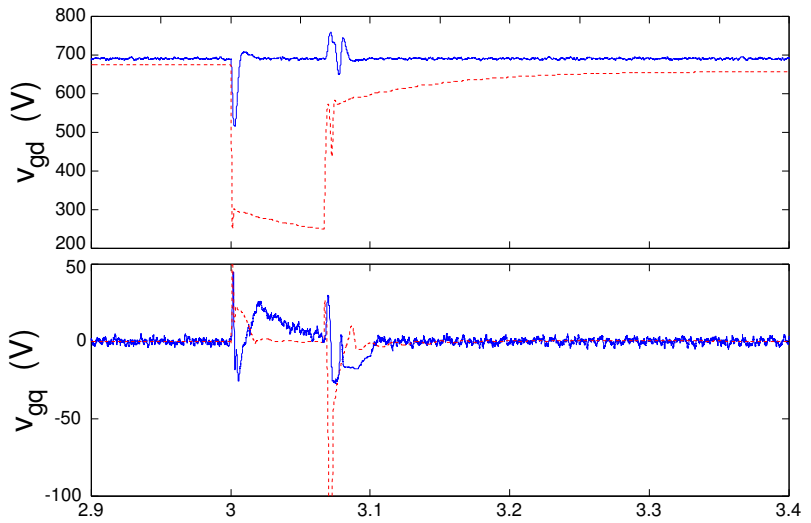

(a) WTG's terminal bus $d-q$ axis voltage.

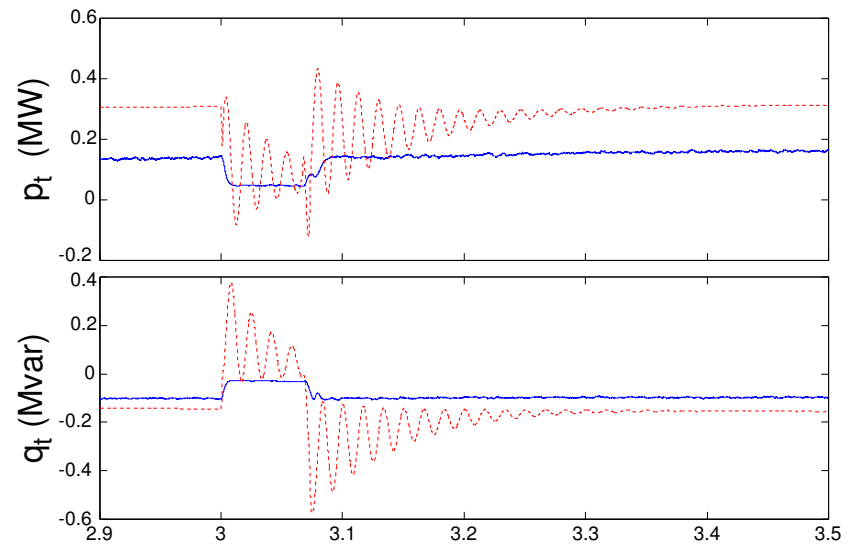

(b) Transmission line power flow.

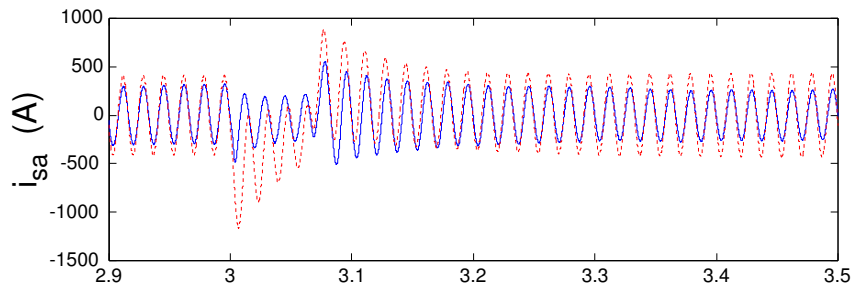

(c) Fault current.

tion Line", T. IEE Japan, Vol. 120-B, No. 2, pp. 180-186, 2000.

[2] D. Kamolyabutra, M. Hojo, Y. Mitani, T. Ise, and K. Tsuji, "Experimental Study on Power System Stabilizing Control Scheme for the SMES with Solid-State Phase Shifter(SuperSMES) using local signals", T. IEE Japan, Vol. 119-B, No. 5, pp. 581-588, 1999.

[3] T. Uranaka, Y. Mitani, and K. Tsuji, "Power System Stabilizing Control by a Superconducting Magnetic Energy Storage with a High Speed Phase Shifter", T. IEE Japan, Vol. 115-B, No. 8, pp. 883-889, 1995.

[4] D. Kamolyabutra, Y. Mitani, and K. Tsuji, "Power System Stabilization by SMES with Series Compensator", T. IEE Japan, Vol. 120-B, No. 12, pp. 1615-1612, 2000.

James J. Skiles, Robert L. Kustom, Ka-Pui Ko, Vincent Wong, Ka-Shu Ko, Frederick Vong, and Keith Klontz, "Performance of a Power Conversion System for Superconducting Magnetic Energy Storage(SMES)" IEEE Transactions on Power System, Vol. 11, No. 4, November 1996, pp. 1718-1723.

[5] Byung M. Han, and George G. Karady, "New combined power-conditioning system for superconducting magnetic energy Storage" , ELSEVIR, Elecric Power Sytems Research, 37,1996, pp. $79-85$. 

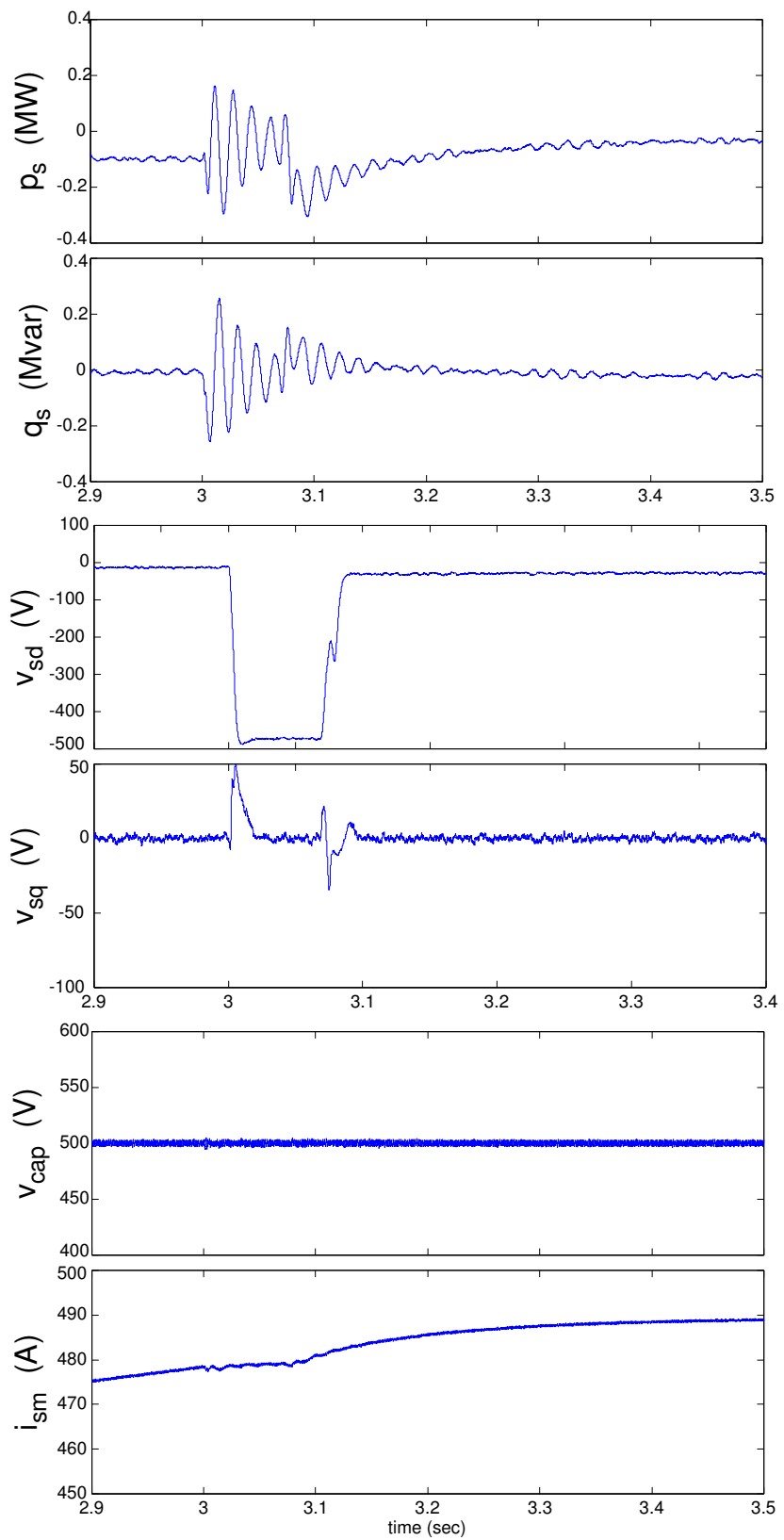

(d) Output and dc-side quantity of the series and parallel compensator.

Fig. 9. Ground fault simulation results.

[6] T. Matsuzaka, K. Tsuchiya, "Study on Stabilization of a Wind Generation Power Fluctuation", T. IEE Japan, Vol.117-B, No.5, pp. 625-633 (1997-5)(in Japanese) 